\title{
A RECEPÇÃO CRÍTICA DE JOSÉ SARAMAGO NO BRASIL ${ }^{1}$
}

Bruno Brizotto ${ }^{2}$

Cecil Jeanine Albert Zinani ${ }^{3}$

RESUMO: Exame da recepção crítica do escritor português José Saramago por meio do levantamento de teses e dissertações já defendidas em universidades brasileiras, especialmente na Universidade de São Paulo, na Universidade Federal do Rio Grande do Sul e na Pontifícia Universidade Católica do Rio Grande do Sul. Ao examinar tais produções críticas, pretende-se verificar quais obras do escritor luso são alvo de maiores estudos, quais as temáticas dominantes e o direcionamento teórico do estudo. A partir disso, será possível constatar como a produção ficcional de Saramago é recebida e analisada de forma crítica pelas universidades citadas.

PALAVRAS-CHAVE: Recepção crítica; José Saramago; Literatura Portuguesa.

\section{THE CRITICAL RECEPTION OF JOSÉ SARAMAGO IN BRAZIL}

ABSTRACT: Examination of the critical reception of the Portuguese writer José Saramago through the survey of theses and dissertations already defended in Brazilian universities, especially the University of São Paulo, the Federal University of Rio Grande do Sul and the Pontifical Catholic University of Rio Grande do Sul. By examining such critical productions, it is intended to verify which works of the Portuguese writer are the subject of larger studies, which are the dominant themes, the theoretical direction of the study. From this, it will be possible to verify how the fictional production of Saramago is critically received and analyzed by the universities mentioned.

KEYWORDS: Critical reception; José Saramago; Portuguese Literature.

\footnotetext{
1 Originalmente comunicação proferida a 26 de junho de 2012, no "Colóquio Portugal no Brasil: a cena do Rio Grande do Sul”, realizado na Pontifícia Universidade Católica do Rio Grande do Sul (PUCRS), nos dias 25 e 26 de junho de 2012.

2 Mestrando no Programa de Pós-Graduação em Letras, Cultura e Regionalidade da Universidade de Caxias do Sul (UCS).

3 Doutora em Letras pela Universidade Federal do Rio Grande do Sul. Professora e pesquisadora na Universidade de Caxias do Sul (UCS).
} 


\section{Derassisossege}

José Saramago (1922-2010) é considerado um dos maiores escritores da Literatura Portuguesa e, consequentemente, da Literatura Ocidental, seja pelo fato de suas obras serem traduzidas para mais de 30 idiomas, seja pelo fato de ser "o único escritor de língua portuguesa que mereceu de Harold Bloom sua inclusão na série Bloom's modern critical views, coleção de textos críticos sobre os mais lidos e respeitados autores [...]" (LAITANO, 2009, p. 10). Pertencente à prosa de ficção conhecida como “pós-25 de abril de 1974", a qual apresenta como marco indicativo "a repercussão calorosa no estrangeiro" (MOISÉS, 2008, p. 525), Saramago imprimiu às letras portuguesas um estilo próprio, "marcado pela linguagem correntia, coloquial, sem rebuscamentos, que o vincula às impressões do dia-adia, tornando-se acessível a toda espécie de leitor.” (MOISÉS, 2008, p. 525-526). Segundo Moisés (2008, p. 527), a ficção de José Saramago caracteriza-se pelo "mais cerrado realismo", erguendo-se "sobre um tripé, composto pela História, os temas imprevistos, originais, e a ideologia.” Dono de uma produção invejável, Saramago alcançou o ápice após os anos 1980, com títulos como Levantado do chão (1980), Memorial do Convento (1982), O ano da morte de Ricardo Reis (1984), História do Cerco de Lisboa (1989), O Evangelho segundo Jesus Cristo (1991), Ensaio sobre a cegueira (1995), Todos os nomes (1997), O bomem duplicado (2003), Ensaio sobre a lucidez. (2004), As intermitências da morte (2006), Caim (2009) e o póstumo Claraboia (2011), fato que granjeou o renome de que desfruta, sobretudo após ter sido agraciado com o prêmio Nobel de 1998.

Importa também considerar a importância das teorias recepcionais para a análise do fato literário, destacando-se a Sociologia da Leitura e a Estética da Recepção, arroladas por Tadié (1992) como integrantes da Sociologia da Literatura, que "não se ocupa apenas do autor e da obra, mas, também, do público" (TADIÉ, 1992, p. 184), figurando aí as duas disciplinas citadas. Tanto a Sociologia da Leitura (Q. D. Leavis, Jacques Leenhardt, Pierre Józsa, Robert Escarpit) quanto a Estética da Recepção (Hans Robert Jauss, Wolfgang Iser) ocupam-se da reação do público em relação às obras literárias, cada uma com uma perspectiva de estudo bem definida. Ao considerar a contribuição dessas vertentes teóricas, fica mais clara a posição do leitor no ato da leitura. Contudo, o tipo de leitor considerado neste escrito não é o leitor popular, médio; é o leitor crítico, aquele que realizou a leitura de determinado romance de Saramago em uma perspectiva crítica, ou seja, à leitura do 
romance estará incluído um direcionamento teórico específico. Portanto, configura-se, assim, um público específico: alunos de programas de pós-graduação (hoje, mestres e doutores) que contribuem para a ampliação da fortuna crítica do escritor português, além de transmitirem à crítica literária brasileira outra forma de ver o fato literário.

O propósito deste artigo consiste em examinar um aspecto da recepção crítica do escritor português José Saramago, por meio do levantamento de teses e dissertações já defendidas em universidades brasileiras, especialmente na Universidade de São Paulo, na Universidade Federal do Rio Grande do Sul e na Pontifícia Universidade Católica do Rio Grande do Sul. O corpus total divide-se da seguinte maneira: onze dissertações (sete defendidas na USP, três na UFRGS, e uma ${ }^{4}$ na PUCRS) e duas teses (ambas defendidas na USP), entre os anos de 2006 e 2011. ${ }^{5}$ Levando em conta tais produções críticas sobre a obra de Saramago, três critérios orientarão este estudo: (1) quais obras do escritor luso são alvo de maiores estudos, (2) quais as temáticas dominantes e (3) qual o direcionamento teórico do estudo.

Pela análise realizada, as seguintes obras de Saramago foram utilizadas como corpus para a construção das dissertações e teses: Ensaio sobre a cegueira (quatro ocorrências), $O$ Evangelho segundo Jesus Cristo (duas ocorrências), O homem duplicado (duas ocorrências), Todos os nomes (duas ocorrências), Levantado do chão (duas ocorrências), O ano da morte de Ricardo Reis (duas ocorrências), e as obras A caverna, Ensaio sobre a lucider, As pequenas memórias, Manual de pintura e caligrafia, Memorial do Convento e A segunda vida de Francisco de Assis com apenas uma ocorrência para cada uma. Constata-se, assim, que a obra Ensaio sobre a cegueira recebeu a maior atenção.

As temáticas dominantes podem ser arroladas em cinco categorias: (1) a temática do duplo; (2) interpretação das obras de Saramago em diálogo com outras deste autor, bem como com autores de outros sistemas literários, constituindo-se em um exercício de

\footnotetext{
4 A pesquisa por "José Saramago" no "Banco de dados da PUCRS: Teses e Dissertações" encontrou um corpus considerável de teses e dissertações, contudo apenas duas estavam disponíveis para visualização digital, visto que as demais ainda não passaram pelo processo de digitalização.

${ }^{5}$ A justificativa para esse recorte temporal, bem como para a escolha de tais universidades, está fundamentada no seguinte motivo: após pesquisa intensiva em bancos de teses e dissertações de diversas instituições de ensino superior brasileiras, ação que tomou como base o período que vai de 2001 a 2011, chegou-se à conclusão de que o período de 2006 a 2011 foi o mais produtivo para a ampliação da fortuna crítica de José Saramago, tendo como local propício para isso as três universidades supracitadas. Some-se a isso o fato de essas três instituições apresentarem contínua produção de material crítico (coletâneas de artigos/ensaios, dissertações, teses, comunicações) sobre as literaturas de língua portuguesa, além de realizarem eventos que visam contribuir para um maior aprofundamento do estudo de tais literaturas.
} 
literatura comparada; (3) a intertextualidade; (4) as relações entre Literatura e História e (5) a temática do espaço. Partindo de tais categorias temáticas, ficará mais claro qual o direcionamento teórico do estudo, que constitui um dos três eixos norteadores deste trabalho. Além disso, cumpre advertir que as dissertações e teses não primam por uma única temática, valendo-se de outras, como é o caso de "A Ordem e o Caos: Plauto e José Saramago", de Nefatalin Gonçalves Neto, que articula a questão do duplo com a literatura comparada e a intertextualidade.

A primeira categoria, a temática do duplo, compreende duas dissertações: “A construção duplicada em O homem duplicado", de Francisco das Chagas Alves (USP, 2010) e “A Ordem e o Caos: Plauto e José Saramago", de Nefatalin Gonçalves Neto (USP, 2010). A primeira dissertação investiga "o tema dos duplos em O homem duplicado [...] por meio da análise de trechos do romance", buscando "verificar como o autor retoma o tema do duplo para abordar a cisão da identidade do homem contemporâneo." (ALVES, 2010, p. 5). A segunda, por sua vez, tem como objetivo "analisar as obras Amphytruo [...] e O Homem Duplicado [...] por meio da investigação do tema do duplo presente nas duas obras em questão.” (GONÇALVES NETO, 2010, p. 8). O duplo, em linhas gerais, é uma entidade que duplica o "eu", destacando-se dele e autonomizando-se a partir desse desdobramento. Gera-se a partir do "eu” para, de imediato, dele se individualizar e adquirir existência própria. A sua coexistência com o "eu” de que é originário, contudo, nem sempre é pacífica. Podem ocorrer duas modalidades: a) o duplo apresenta, segundo o julgamento do "eu", características positivas, sendo resultante de um processo de identificação entre o "eu" e o seu duplo; b) o duplo apresenta, de acordo com o julgamento do "eu", características negativas, resultantes de um processo de oposição entre o "eu" e o seu duplo, pela constatação de uma não correspondência de traços ou características afins. Sob essa dupla perspectiva, as duas dissertações que versam sobre essa temática recaem na segunda modalidade, efetivando a cisão da identidade e a crise identitária. No que toca ao direcionamento teórico, foram utilizados autores que tratam o tema do duplo, como Carl F. Keppler - em The literature of the second self (1972), no qual faz referência ao trabalho de Otto Rank sobre o duplo, referindo-se ao ensaio intitulado Der Doppel Gänger [O duplo] -, Nicole Bravo, Sigmund Freud e Friedrich Nietzsche. Conforme já referido, a dissertação de Gonçalves Neto (2010) realiza a leitura do duplo em O homem duplicado e Amphytruo (O Anfitrião), do escritor latino Plauto, através da literatura comparada e da intertextualidade, 
estabelecendo relações entre essas três temáticas. A ligação intertextual entre as obras é elucidada pelo autor: "[...] o diálogo entre as obras se estabelece por meio do mito de Anfitrião, que é retomado pelos dois escritores transfigurado pela intenção de cada um.” (GONÇALVES NETO, 2010, p. 8).

A segunda categoria, que opera com a literatura comparada, faz-se presente em três dissertações: "Alegorias do mundo em Saramago", de Maiquel Röhrig (UFRGS, 2011), "Personagens engajadas em sociedades de classes: uma leitura comparativa entre $O$ tempo e 0 vento, de Érico Veríssimo, e Levantado do chão, de José Saramago”, de Iraci Lacerda (USP, 2007) e "As pequenas memórias na ficção de José Saramago: a recordação da infância como matéria literária", de Paloma Esteves Laitano (PUCRS, 2009). A primeira "interpreta as obras Ensaio sobre a cegueira (1995), A caverna (2000) e Ensaio sobre a lucidez (2004) a partir de uma perspectiva interdisciplinar sustentada por aproximações intertextuais entre literatura e filosofia." (RÖHRIG, 2011, p. 4). A segunda analisa "os aspectos semelhantes entre as personagens em atividade política", ressaltando "aspectos diferenciadores como classe social, ideal socialista e intensidade de atuação, a fim de acompanharmos a trajetória do engajamento durante o século XX" (LACERDA, 2007, p. 7). A terceira dissertação estabelece um "estudo comparativo entre a matéria recordada na obra As pequenas memórias [...] e a ficcionalização dessas vivências no corpus de romances estabelecido pelo próprio autor, no livro memorialístico [...]" (LAITANO, 2009, p. 6). As obras que Saramago refere no livro de memórias são Manual de pintura e caligrafia, Memorial do convento, O Evangelho segundo Jesus Cristo, Ensaio sobre a cegueira e Todos os nomes. A perspectiva comparada, conforme vista nesses três trabalhos, é útil, pois permite ao estudioso dialogar com obras de sistemas literários diferentes, além de colocar frente a frente obras do mesmo autor. $\mathrm{O}$ direcionamento teórico desses três estudos comparados é diverso, passando por Fredric Jameson, Walter Benjamin, István Mészáros, Benjamin Abdala Jr., Mikhail Bakhtin, Irving Howe, Marta Harnecker, Paul Singer, Jean-Paul Sartre, George Gusdorf, Gaston Bachelard, Gérard Genette, entre outros.

A terceira categoria, relativa à intertextualidade, pode ser identificada como temática predominante nas seguintes dissertações: "Ricardo Reis: ficção da ficção", de Priscila de Oliveira Ferreira (UFRGS, 2006), "O Ano da Morte de Ricardo Reis: o leitor no jogo da ficção", de Regina Cláudia Kawamura (USP, 2009), "O evangelho segundo o narrador: o papel do narrador em O evangelho segundo Jesus Cristo de José Saramago", de Paulo Nedel 
(UFRGS, 2006) e "Do santo ao homem: Francisco de Assis sob o olhar de Saramago", de Ana Paula Borges (USP, 2008). A primeira dissertação analisa "a relação entre os dois Ricardos", observando "o que os aproxima e o que os distancia” (FERREIRA, 2006, p. 6). O direcionamento teórico reúne autores como Julia Kristeva, Mikhail Bakhtin, Georg Lukács, Tânia Franco Carvalhal, entre outros. Percebe-se aí o diálogo com a poesia de Fernando Pessoa (o heterônimo Ricardo Reis) e a apropriação de conceitos da teoria da intertextualidade, do dialogismo, do herói degradado, entre outros. A segunda também parte da obra $O$ ano da morte de Ricardo Reis, levando em conta o ponto de vista da intertextualidade, apresentando o seu traço de destaque: o processo intertextual se constrói a partir do repertório do leitor, que "interage com as informações do texto, a fim de construir o sentido, num jogo de ressignificação com os intertextos que permeiam a obra" (KAWAMURA, 2009, p. 5). Nessa reflexão, está posto o jogo da leitura, "que está presente no interior do romance, e que, por sua vez, induz o leitor a refletir sobre a relevância do seu papel como produtor de sentido diante do texto" (KAWAMURA, 2009, p. 5). Teóricos como Wolfgang Iser, Jean-Paul Sartre, Luiz Costa Lima, Beth Brait, Umberto Eco, Johan Huizinga, entre outros, são utilizados como literatura básica para a construção do instrumental teórico dessa dissertação. A terceira leva em conta a perspectiva da intertextualidade ao "analisar o narrador d'O evangelho segundo Jesus Cristo [...], mantendo intenso diálogo com a História que nos chegou através dos relatos dos Evangelhos bíblicos" (NEDEL, 2006, p. 5). Como apoio teórico, o autor vale-se de Tânia Franco Carvalhal, Affonso Romano de Sant'Anna, Mikhail Bakhtin e Linda Hutcheon, além de Merril Tenney, Urbano Zilles e José Hildebrando Dacanal para a contextualização sobre a Bíblia, os apócrifos, Jesus e os evangelistas. A quarta dissertação, por sua vez, analisa a relação intertextual entre o santo católico São Francisco de Assis e a proposta de Saramago, que "em via oposta às fontes franciscanas, desconstrói o santo e reconstrói o homem Francisco de Assis" (BORGES, 2008, p. 7). O direcionamento teórico abrange autores como José Oliveira Barata e Sábato Magaldi, que teorizam sobre o teatro, Umberto Eco, Linda Hutcheon, Affonso Romano de Sant'Anna, além de biógrafos oficiais do santo, como Tomás de Celano e São Boaventura.

A quarta categoria, referente às relações entre o discurso histórico e o literário, pode ser examinada pelas seguintes dissertações: "O evangelho segundo o narrador: o papel do narrador em O evangelho segundo Jesus Cristo de José Saramago", de Paulo Nedel 
(UFRGS, 2006) e "História e Poder: uma leitura de Levantado do Chão", de Camile Carolina Tesche (USP, 2007). A dissertação de Nedel (2006), ao mesmo tempo em que aborda o diálogo intertextual entre o Jesus dos Evangelhos bíblicos e o proposto por Saramago, o faz levando em conta as relações entre a Literatura e a História, valendo-se dos principais teóricos dessa área, como Paul Ricoeur, Hayden White, Georges Duby e Linda Hutcheon, “como também comentários de José Saramago sobre sua atividade de escritor preocupado com a reescrita histórica" (NEDEL, 2006, p. 11). O estudioso também leva em consideração como as relações entre a Literatura e a História se constroem na literatura portuguesa através de três expoentes: Fernão Lopes, Alexandre Herculano e José Saramago. A análise do narrador se faz pelo uso dos autores Cândida Vilares Gancho e Norman Friedman (via Lígia Chiappini Moraes Leite) e Gérard Genette (via Carlos Reis). A dissertação de Tesche (2007) "tem como objetivo analisar de que modo o romance Levantado do Chão [...] apropria-se de episódios de grande importância histórica para Portugal, como a chegada da I República em 1910, a ascensão da ditadura salazarista, em 1926, e a Revolução dos Cravos, em 1974” (TESCHE, 2007, p. 8). A autora também privilegia as articulações entre os discursos (ideologia) e as práticas sociais. Dentre os teóricos, destacam-se: Jacques Le Goff, Eric Hobsbawn, Paul Veyne, Linda Hutcheon, Mikhail Bakhtin, Louis Althusser e Andrew Vincent.

A quinta categoria, atinente à temática do espaço, compreende a dissertação "Entre as trevas e a luz: o percurso labiríntico em Todos os nomes de José Saramago", de Murilo de Assis Macedo Gomes (USP, 2009) e as teses “Os espaços infernais e labirínticos em Ensaio sobre a cegueira", de Nanci Geroldo Richter (USP, 2007) e "Tempo, espaço e autoconsciência: a construção da identidade em Ensaio sobre a Cegueira", de Angela Ignatti Silva (USP, 2008). A dissertação de Gomes (2009) “visa mostrar de que modo o caminho trilhado pela personagem protagonista do romance constitui um processo de autoconhecimento em meio às múltiplas possibilidades de um espaço que se configura como labiríntico" (GOMES, 2009, p. 6). O percurso analítico dessa dissertação abordou os conceitos de símbolo, espaço, lugar, não-lugar, individuação e anima, conforme teorizações propostas por Carl Gustav Jung, Gilbert Durand, Marc Augé, Gaston Bachelard e Michel de Certeau. Os espaços da porta e da escada são tão importantes enquanto símbolos, pois "levam a personagem de uma condição à outra, estabelecendo mudanças que variam entre o eu e o outro e entre as trevas e a luz [...]" (GOMES, 2009, p. 6). Gomes (2009) também 
estabelece a (re)construção da imagem do labirinto, tanto mitologicamente (mito do labirinto do Minotauro) quanto individualmente (pelo próprio personagem, o Sr. José), constituindo um diálogo intertextual entre o mito grego e a narrativa de Saramago, na qual o Sr. José busca por sua anima através dos espaços interiores e exteriores. A tese de Richter (2007) apresenta como objetivo "a análise dos espaços e suas influências no modo de ser das personagens principais do romance Ensaio sobre a cegueira [...]” (RICHTER, 2007, p. 4). Para efetivar tal estudo, a autora analisou diferentes tipologias espaciais no romance, tais como espaços interiores, exteriores, ínferos e labirínticos, estabelecendo conexão com o tema proposto pelo narrador. Os espaços ínferos são o manicômio e a igreja; os labirínticos, as ruas, a cidade e o supermercado; os horizontais e verticais, as casas de algumas personagens centrais. O instrumental teórico construiu-se por meio de autores como Marc Augé, Gaston Bachelard e Antonio Candido. Por fim, a tese de Silva (2008) "tem como objetivo o exame dos cronotopos no romance Ensaio sobre a Cegueira [...], desenvolvido mediante o estudo do manicômio, das ruas, das casas, entre outros" (SILVA, 2008, p. 7). Utilizado originariamente por Albert Einstein na elaboração da teoria da relatividade e concebido por Bakhtin (2002, p. 211) como "a expressão da indissolubilidade de espaço e tempo (tempo como a quarta dimensão do espaço)", o emprego do termo cronotopo permitiu à estudiosa "adentrar o campo da autoconsciência das personagens, o qual revela a ampliação do âmbito de visão delas sobre si mesmas e sobre os outros" (SILVA, 2008, p. 7). Ainda segundo Silva (2007, p. 7), “a autoconsciência desemboca na questão da construção da identidade que descortina a imagem do homem contemporâneo, cindido, em conflito com seu tempo e seu espaço." O direcionamento teórico abarca autores como Mikhail Bakhtin, Stuart Hall, Marc Augé, Georges Gusdorf, Antonio Candido, Jurgen Habermas, Fredric Jameson, Jean-François Lyotard, Sergio Paulo Rouanet, entre outros.

Enfim, percebe-se que a investigação crítica em torno da obra de José Saramago é de uma pluralidade impressionante, seja pelo fato de cada dissertação/tese utilizar uma metodologia própria, um instrumental teórico decorrente de uma temática claramente estabelecida, seja pelo fato de a obra do escritor luso abrir-se para múltiplas possibilidades de leitura, seguindo o preceito máximo da obra de arte literária. Reforça-se, assim, o papel do leitor no ato da leitura, o qual não se efetiva sem o autor e a obra, constituindo tal 
relação triádica um processo interdependente, como bem registrou Antonio Candido há exatos 49 anos, em Literatura e Sociedade.

\section{REFERÊNCIAS BIBLIOGRÁFICAS}

ALVES, Francisco das Chagas Jacinto. "A construção duplicada em O homem duplicado". Dissertação (Mestrado). Faculdade de Filosofia, Letras e Ciências Humanas, Universidade de São Paulo, 2010, 89 p.

BAKHTIN, Mikhail. Questões de literatura e de estética: a teoria do romance. Trad. Aurora Bernardini et al. 5. ed. São Paulo: Hucitec, 2002.

BORGES, Ana Paula Carraro. "Do santo ao homem: Francisco de Assis sob o olhar de Saramago”. Dissertação (Mestrado). Faculdade de Filosofia, Letras e Ciências Humanas, Universidade de São Paulo, 2008, 101 p.

FERREIRA, Priscila de Oliveira. "Ricardo Reis: ficção da ficção". Dissertação (Mestrado). Programa de Pós-Graduação em Letras, Universidade Federal do Rio Grande do Sul, 2006, $145 \mathrm{p}$.

GOMES, Murilo de Assis Macedo. "Entre as trevas e a luz: o percurso labiríntico em Todos os nomes de José Saramago". Dissertação (Mestrado). Faculdade de Filosofia, Letras e Ciências Humanas, Universidade de São Paulo, 2009, 135 p.

GONÇALVES NETO, Nefatalin. "A Ordem e o Caos: Plauto e José Saramago". Dissertação (Mestrado em Literatura Portuguesa). Faculdade de Filosofia, Letras e Ciências Humanas, Universidade de São Paulo, 2010, 157 p.

KAWAMURA, Regina Cláudia. "O Ano da Morte de Ricardo Reis: o leitor no jogo da ficção”. Dissertação (Mestrado). Faculdade de Filosofia, Letras e Ciências Humanas, Universidade de São Paulo, 2009, 125 p.

KEPPLER, Carl F. The literature of the second self. Arizona: The University of Arizona Press, 1972.

LACERDA, Iraci Judite. "Personagens engajadas em sociedade de classes: uma leitura comparativa de O Tempo e o Vento, de Érico Veríssimo, e Levantado do Chão, de José Saramago". Dissertação (Mestrado). Faculdade de Filosofia, Letras e Ciências Humanas, Universidade de São Paulo, 2007, 173 p. 
LAITANO, Paloma Esteves. "As pequenas memórias na ficção de José Saramago: a recordação da infância como matéria literária". Dissertação (Mestrado). Faculdade de Letras, Pontifícia Universidade Católica do Rio Grande do Sul, 2009, 129 p.

MOISÉS, Massaud. A literatura portuguesa. 35. ed. rev. e atual. São Paulo: Cultrix, 2008.

NEDEL, Paulo Augusto. "O evangelho segundo o narrador: o papel do narrador em $O$ evangelho segundo Jesus Cristo de José Saramago". Dissertação (Mestrado). Programa de PósGraduação em Letras, Universidade Federal do Rio Grande do Sul, 2006, 226 p.

RICHTER, Nanci Geroldo. "Os espaços infernais e labirínticos em Ensaio sobre a cegueira”. Tese (Doutorado). Faculdade de Filosofia, Letras e Ciências Humanas, Universidade de São Paulo, 2007, 165 p.

RÖHRIG, Maiquel. "Alegorias do mundo em Saramago”. Dissertação (Mestrado). Programa de Pós-Graduação em Letras, Universidade Federal do Rio Grande do Sul, 2011, $126 \mathrm{p}$.

SILVA, Angela Ignatti. "Tempo, espaço e autoconsciência: a construção da identidade em Ensaio sobre a Cegueira". Tese (Doutorado). Faculdade de Filosofia, Letras e Ciências Humanas, Universidade de São Paulo, 2008, 217 p.

TADIÉ, Jean Yves. A crítica literária no século XX. Trad. Wilma Freitas Ronald de Carvalho. Rio de Janeiro: Bertrand Brasil, 1992.

TESCHE, Camila Carolina Pereira da Silva. "História e Poder: uma leitura de Levantado do Chão". Dissertação (Mestrado). Faculdade de Filosofia, Letras e Ciências Humanas, Universidade de São Paulo, 2007, 133 p.

Artigo recebido em 01 de maio de 2014

Artigo aceito em 20 de junho de 2014 